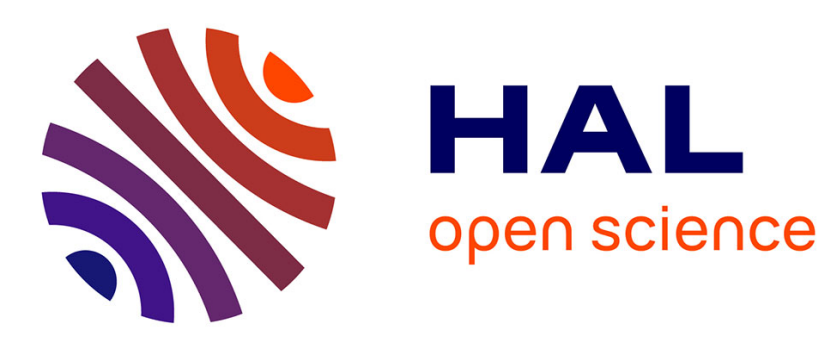

\title{
Green InGaN/GaN based LEDs: high luminance and blue shift
}

\author{
Anis Daami, François Olivier, Ludovic Dupré, Christophe Licitra, Franck \\ Henry, François Templier, Stéphanie Le Calvez
}

\section{To cite this version:}

Anis Daami, François Olivier, Ludovic Dupré, Christophe Licitra, Franck Henry, et al.. Green InGaN/GaN based LEDs: high luminance and blue shift. Gallium Nitride Materials and Devices XIV, SPIE, Feb 2019, San Francisco, United States. pp.21, 10.1117/12.2509396 . cea-02941414v2

\section{HAL Id: cea-02941414 https://hal-cea.archives-ouvertes.fr/cea-02941414v2}

Submitted on 29 Sep 2020

HAL is a multi-disciplinary open access archive for the deposit and dissemination of scientific research documents, whether they are published or not. The documents may come from teaching and research institutions in France or abroad, or from public or private research centers.
L'archive ouverte pluridisciplinaire HAL, est destinée au dépôt et à la diffusion de documents scientifiques de niveau recherche, publiés ou non, émanant des établissements d'enseignement et de recherche français ou étrangers, des laboratoires publics ou privés. 


\section{Clean Sky2}
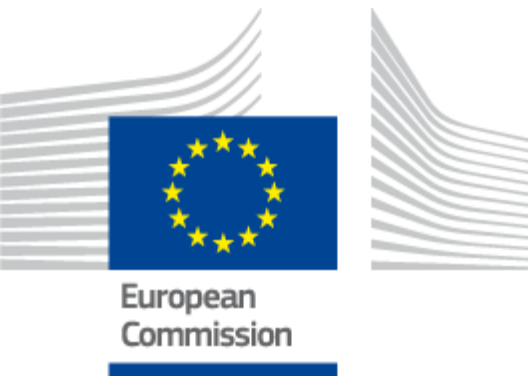

\begin{tabular}{|c|c|}
\hline Document Title & Green InGaN/GaN LEDs: High luminance and blue shift \\
\hline Authors & 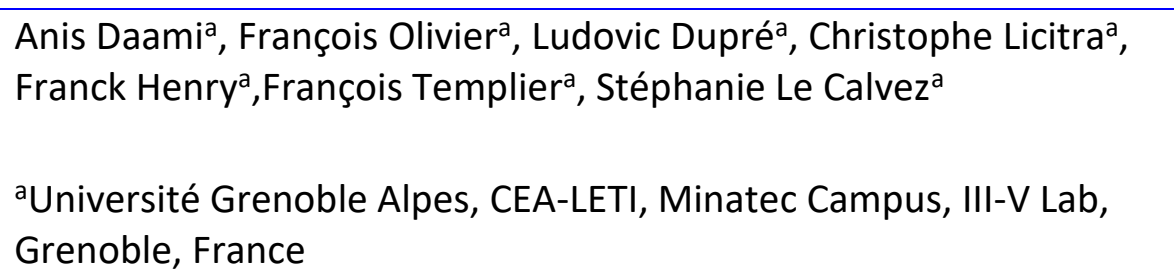 \\
\hline Issue date & March 1, 2019 \\
\hline Journal & $\begin{array}{l}\text { SPIE Proceedings Volume 10918, Gallium Nitride Materials and } \\
\text { Devices XIV; 109180M (2019) }\end{array}$ \\
\hline Doi & $10.1117 / 12.2509396$ \\
\hline Acknowledgment & $\begin{array}{l}\text { This project has received funding from the Clean Sky } 2 \text { Joint } \\
\text { Undertaking under the European Union's Horizon } 2020 \text { research } \\
\text { and innovation programme under grant agreement No } 755497 .\end{array}$ \\
\hline Disclaimer & $\begin{array}{l}\text { The content of this article reflects only the author's view. } \\
\text { The Clean Sky Joint Undertaking is not responsible for any use that } \\
\text { may be made of the information it contains. }\end{array}$ \\
\hline
\end{tabular}




\title{
Green InGaN/GaN LEDs: High luminance and blue shift
}

\author{
Anis Daami*a ${ }^{*}$ François Olivier ${ }^{\mathrm{a}}$, Ludovic Dupréa ${ }^{\text {, Christophe Licitra }}{ }^{\mathrm{a}}$, Franck Henry ${ }^{\mathrm{a}}$, \\ François Templier ${ }^{\mathrm{a}}$, Stéphanie Le Calvez ${ }^{\mathrm{a}}$ \\ ${ }^{a}$ Université Grenoble Alpes, CEA-LETI, Minatec Campus, III-V Lab, Grenoble, France
}

\begin{abstract}
We report in this paper electro-optical results on InGaN/GaN based green micro light-emitting diodes ( $\mu$ LEDs). Currentlight-voltage measurements reveal that the external quantum efficiency (EQE) behavior versus charge injection does not follow the $\mathrm{ABC}$ model prediction. Light-emission homogeneity investigation, carried out by photoluminescence mapping, shows that the Quantum Confinement Starck Effect (QCSE) is less significant at the edges of $\mu$ LEDs. Electroluminescence shows a subsequent color green-to-blue deviation at high carrier injection levels. The extracted spectra at different current injection levels tend to show the appearance of discrete wavelength emissions. These observations may enhance the hypothesis that higher-energy excited-levels in InGaN quantum wells may also contribute to the blue shift, solely attributed to QCSE lessening under intense electric field magnitudes. We hereby present first results dealing with green $\mu$ LEDs electro-optical performances with regards to their size.
\end{abstract}

Keywords: InGaN/GaN, green $\mu \mathrm{LED}$, blue shift, QCSE

\section{INTRODUCTION}

Micro light-emitting diodes ( $\mu$ LEDs) based on InGaN/GaN quantum well structures have seen a significant amount of progress in the last two decades ${ }^{1,2,3}$. New emerging applications such as augmented/mixed or virtual reality are looking forward using micro-displays ( $\mu$-displays) based on these still progressing technologies. However, a majority of studies in literature are mostly dealing with blue emitting $\mu$ LEDs, with fewer investigation papers on green light emitting ones. Actually, the high-content indium incorporation in InGaN alloys, to adjust the emission wavelength to green color, is not an easy process track to deal with.

Nonetheless, green $\mu$ LEDs are well positioned to cover high luminance needing components. Indeed, the eye sensitivity is at its maximum in this range of emitted wavelengths. Furthermore, for specific applications such as see-through glasses, a high brightness level of $5000 \mathrm{~cd} / \mathrm{m}^{2}$ or more is a mandatory keystone to achieve. Nevertheless, quantum efficiency of $\mu$ LEDs is yet a challenging subject when dealing with high luminance levels. Besides, $\mu$ LED size dependence has been thoroughly studied and reported in literature, but mostly for blue color emitting ones ${ }^{4,5}$. A lack of comprehension of size effect is then still to be filled for these green light-emitting diodes dedicated to specific $\mu$-displays applications.

This paper deals with an electro-optical study on different sized green $\mu$ LEDs. First, quantum efficiency performance is analyzed versus $\mu$ LED size. In a second part, we focus respectively, on $\mu$ LED emission homogeneity and spectral response behaviors versus electrical injection.

\section{ELECTRO-OPTICAL INVESTIGATION}

\subsection{Current-Voltage characteristics}

Current density versus voltage characteristics of the different measured devices are shown on figure 1. At first glance, the current density seems independent of the $\mu$ LED size on a large bias range. Larger devices (500 $\mu \mathrm{m}$ and $200 \mu \mathrm{m})$ show a slightly lower current density at high voltage values that is attributed to a probable deviation of the series resistance from an ideal geometrical law. We have shown in a recent study ${ }^{6}$ that a series resistance variation can have a major impact on the $\mu$ LED current at high voltage. On the other hand, at a bias value lower than the $\mu$ LED threshold voltage, the perceived current density difference is mainly related to the limitation of our apparatus sensitivity. Despite these slight observed differences, we demonstrate once again the robustness of our $\mu$ LED fabrication process ${ }^{7}$.

*anis.daami@cea.fr 


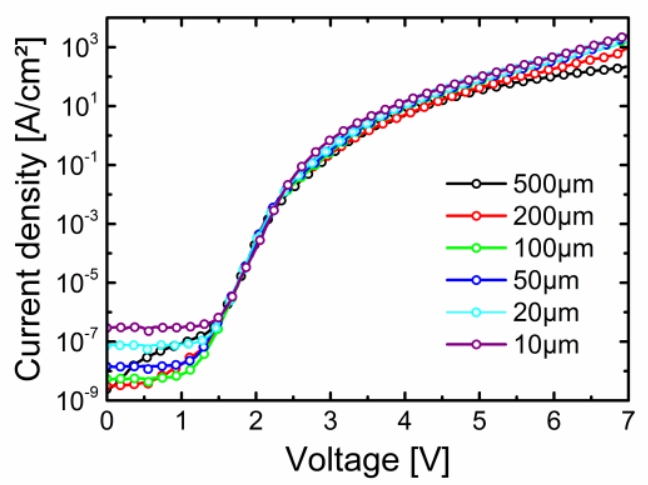

Figure 1. Current density versus voltage characteristics of different square $\mu$ LEDs. Current density is constant on a large bias range whatever the $\mu$ LED size is. The legend denotes the side width of each $\mu$ LED.

\subsection{Optical power and quantum efficiency}

As regards to optical properties of our devices, figure 2(a) shows the measured optical output power versus applied voltage of the different $\mu$ LEDs. The corresponding external quantum efficiency (EQE) of each device are plotted versus current density on figure 2(b). In contrary to what is reported ${ }^{4}$ on our blue LEDs, the optical threshold voltage $\left(\mathrm{V}_{\mathrm{TO}}\right)$ of green $\mu$ LEDs does not seem to vary much in a certain range of geometry (width $\geq 50 \mu \mathrm{m}$ ). The extracted value of $\mathrm{V}_{\text {TO }}$ in this range of geometry is around $2.1 \pm 0.05 \mathrm{~V}$. For smaller $\mu \mathrm{LEDs}, \mathrm{V}_{\text {то }}$ begins to shift, attaining $2.5 \mathrm{~V}$ for a $10 \mu \mathrm{m} \mu \mathrm{LED}$.

Moreover, the optical output power of large devices, shows two distinct regimes. At low voltage, a first rapid increase is observed. Then, this fast upturn slows down, showing a 'kink' like effect. In a second time, the power rises again with bias until a saturation regime due to droop is attained. The echo of these two regimes is evident on the EQE curves of large devices. Indeed a first increase is perceived, then the $\mathrm{EQE}$ reaches a plateau (EQE 2\%), corresponding to the optical power output 'kink' region. Afterwards, the $\mathrm{EQE}$ restarts to increase reaching a maximum $\mathrm{EQE} \mathrm{E}_{\max }=5 \%$, before sinking down due to droop effect.

It is worth pointing out that the first rapid regime seems to disappear when the size of the $\mu$ LED shrinks. This is evident on $\mathrm{EQE}$ curves where the plateau regime tends to vanish for small geometries. Besides, the EQE threshold current density moves to higher values for the small devices (width $\leq 20 \mathrm{um}$ ). We hereafter, emit the hypothesis that the fading of the rapid optical output regime and the shift of the optical threshold voltage $\mathrm{V}_{\mathrm{TO}}$ are correlated.
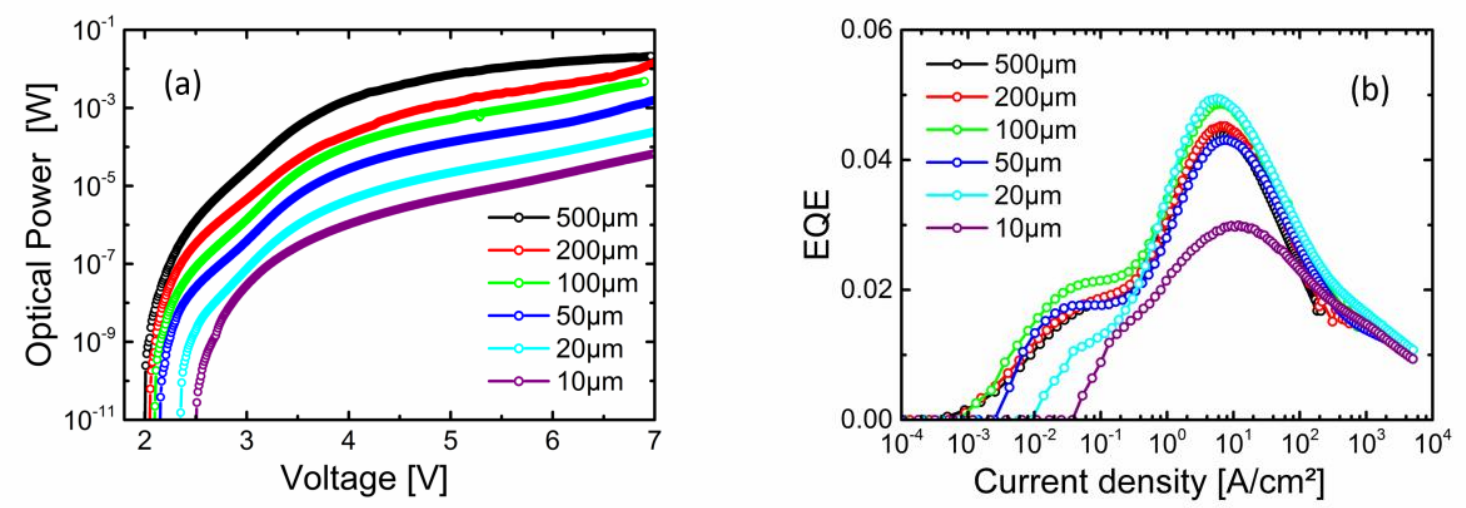

Figure 2. (a) Optical power versus voltage and (b) external quantum efficiency versus current density characteristics of different square $\mu$ LEDs. Two different optical regimes are depicted on large scale $\mu$ LEDs. The $1^{\text {st }}$ regime tends to disappear for smaller $\mu$ LEDs. It is worth noting that the $1^{\text {st }}$ regime vanishing is correlated to the shift of the optical emission threshold also observed on smaller geometry $\mu$ LEDs. 


\subsection{Light emission homogeneity}

Many studies in literature point out the importance of the $\mu$ LED periphery on its optical efficiency ${ }^{8,}{ }^{9}$. Downsizing the device geometry has usually come out with lower optical efficacies. One crucial adopted reason is the perimeter taking over the surface, when the $\mu$ LED size diminishes. Numerous investigations in this direction, have shown the increase of SRH non-radiative recombination. This is primarily related to defects and a bad passivation of $\mu$ LED periphery after etching steps. We have carried out photoluminescence (PL) mapping on a 3 by 3 array of green $\mu$ LEDs $\left(7 \times 7 \mu \mathrm{m}^{2}\right)$ to check the quality of our etching process and light emission homogeneity. Figure 3 shows respectively, the obtained PL intensity and wavelength mappings. Oddly, we observe a higher signal at the edges of the $\mu$ LEDs. Moreover the emitted wavelength is to some extent lower at these boundaries. This observation, presumably points out a less predominant QCSE at the periphery of our devices. Indeed, we suppose a strong relaxation of the lattice constraint at the edges of the $\mu$ LED. This constraint reduction gives rise to a reduced spontaneous polarization in the quantum wells. Hence, the locally emitted light is shifted to a higher energy. Moreover, the reduced band curvature would allow a better recovery of hole and electron wave-functions, explaining the stronger emission intensity. A similar observation has been reported ${ }^{10}$ by Xie et al. using the cathodoluminescence technique.

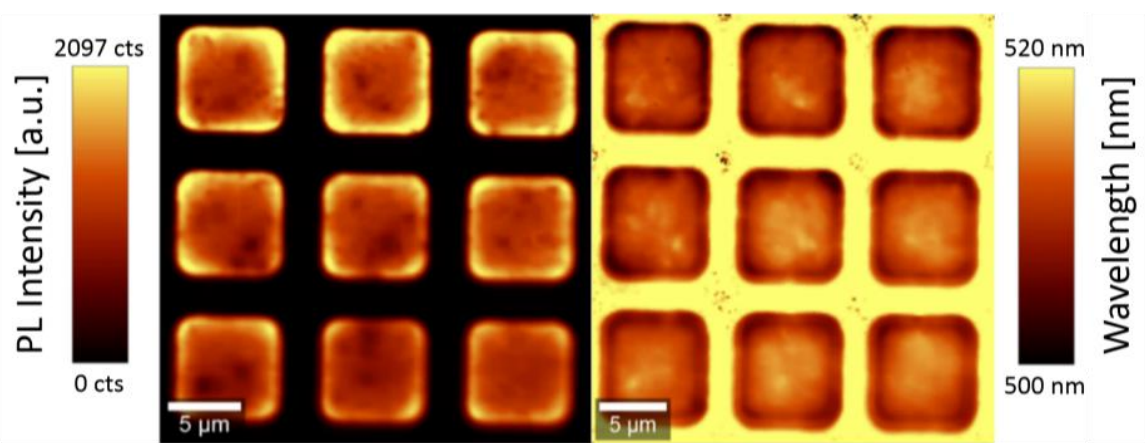

Figure 3. Photoluminescence intensity and wavelength mappings on a $3 \times 37 \mu \mathrm{m}$ squared $\mu$ LEDs array. A higher intensity correlated to a shorter wavelength emission is observed on the edges of $\mu$ LEDs. We suppose a probable lattice relaxation at the edges of $\mu \mathrm{LEDs}$, reducing the QCSE effect behind this observation.

Another important observation shown in figure 4 reveals that light emission homogeneity is bias dependent on larger scale $\mu$ LEDs (100x100 $\mu \mathrm{m}^{2}$ LED example shown). Indeed we can see that at low voltage range, the emission is rather speckled on the surface of the device. This spattered pattern is mainly related to a non-homogeneous indium incorporation in quantum wells. Consequently, this indium spread results in a local optical threshold variation through the device surface itself. Higher content indium spots will have a lower optical threshold voltage, hence emitting at lower bias values. It is regularly reported in literature that high content indium amalgamation with $\mathrm{GaN}$ is a harsh path to consider ${ }^{11}, 12$. Another reason to this light speckle pattern may also come from a local variation of contact resistivity. This electrical deviation can be related to the indium spread, stated above. It can also be due to a non-homogeneous P doping, locally degrading the contact/semiconductor interface ${ }^{13,14}$.

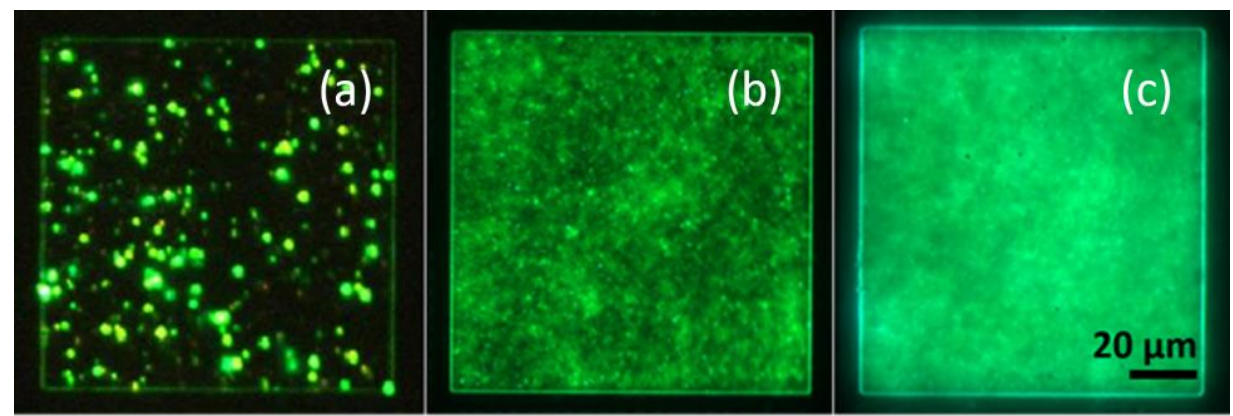

Figure 4. Optical photos of light emission homogeneity on a $100 \times 100 \mu \mathrm{m}^{2}$ green LED at different bias values: (a) $\mathrm{V}=2.2 \mathrm{~V}$,

(b) $\mathrm{V}=3.5 \mathrm{~V}$ and (c) $\mathrm{V}=4.5 \mathrm{~V}$. Note the high luminance spread at low voltage that disappears at higher bias values. 
Regarding smaller area $\mu$ LEDs, usually dedicated to micro-displays, this singularity has to be banned. Indeed luminance homogeneity is one important key factor of micro-displays. This observed spread in luminance tends to disappear when injection bias is driven upwards. Nevertheless, this voltage increase induces the appearance of another oddity. Actually, the emitted-light wavelength shifts towards lower values. More details on this shift are discussed in the next section.

\section{THE BLUE SHIFT DILEMMA}

\subsection{Electroluminescence and color shift}

We carried out electroluminescence measurements on small sized unitary $\mu$ LEDs $(6 \mu \mathrm{m}$ diameter) in order to limit the surface-spread light-emission observed at low injection. Optical photos taken at different applied voltages, presented in figure 5, perceptibly show an intense wavelength shift of the emitted light when injection bias is increased. We clearly see a green to blue transformation of the emitted color.

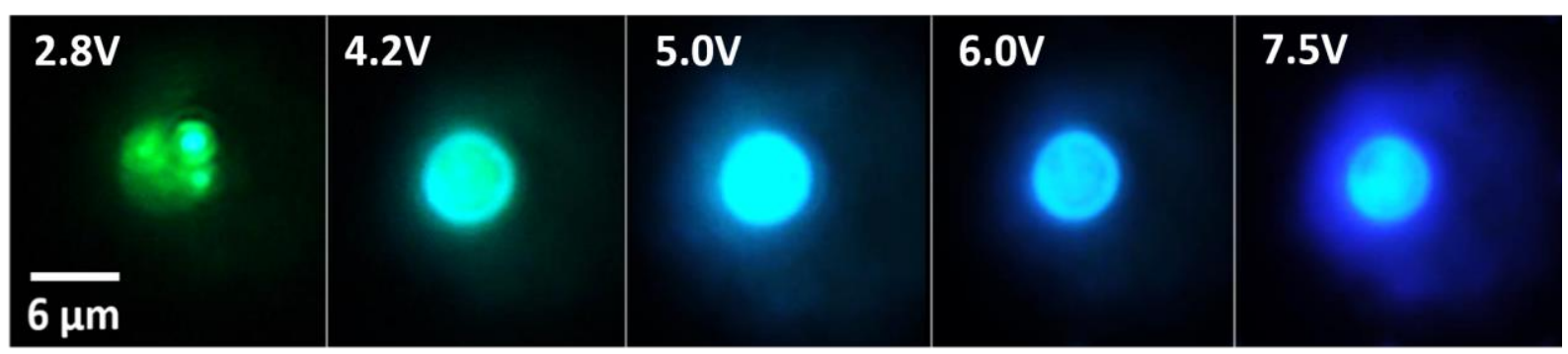

Figure 5. Optical photos of light emission on a $6 \mu \mathrm{m}$ diameter 'green' $\mu$ LED at different bias values. The emitted wavelength is very dependent on applied voltage across the $\mu \mathrm{LED}$. Green color turns to blue when increasing bias from $2.8 \mathrm{~V}$ to $7.5 \mathrm{~V}$.

This important evolution has been quantified, and the color point plotted on a CIE chromaticity 1931 diagram, displayed in figure 6. Each measured point corresponds to an increase of $0.1 \mathrm{~V}$ of the $\mu \mathrm{LED}$ bias, varying from $2.5 \mathrm{~V}$ to $7.5 \mathrm{~V}$. There is no doubt that the emitted wavelength covers a large range on the CIE diagram varying from green $(\lambda=540 \mathrm{~nm})$ to an almost true blue $(\lambda=475 \mathrm{~nm})$.

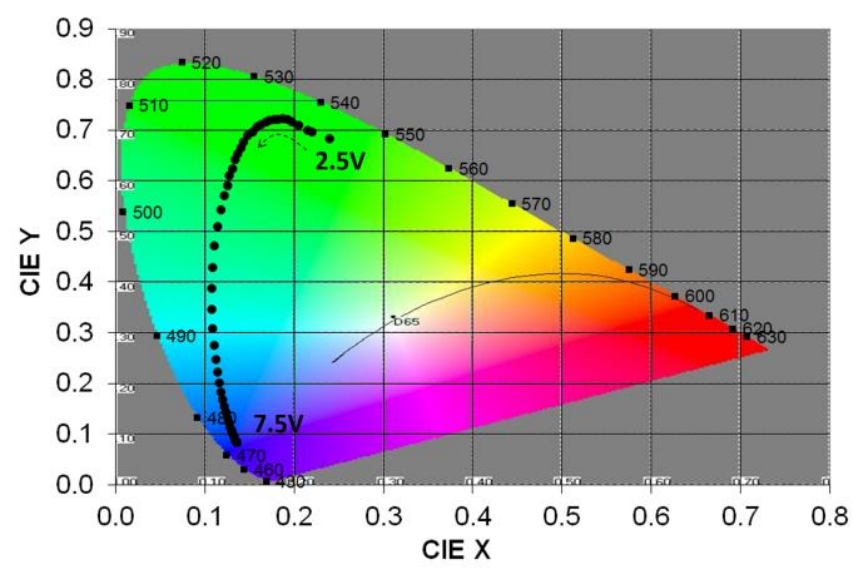

Figure 6. Color point evolution of the emitted light from a green $\mu$ LED plotted on CIE chromaticity 1931 diagram. Bias varies from $2.5 \mathrm{~V}$ to $7.5 \mathrm{~V}$. Each point corresponds to $100 \mathrm{mV}$ increase in voltage. The measured wavelength varies from $540 \mathrm{~nm}$ (green) to $475 \mathrm{~nm}$ (blue).

The wavelength blue shift is also observed in blue emitting $\mu$ LEDs but at a lesser extent. It is usually attributed to the fading, under high voltage, of the Quantum Confined Starck Effect (QCSE). This later is explained by the default presence of a local electric field in the quantum wells. Its magnitude is directly depending on both the spontaneous and piezo-electric polarizations existing in InGaN/GaN light emitting devices ${ }^{15}$. In the case of green $\mu \mathrm{LEDs}$, the high indium content induces 
a huge lattice mismatch, at the barrier/quantum well interface between InGaN and GaN materials. Subsequently, a high charge density appears at the quantum well interfaces. Consequently, a high magnitude piezo-electric field, related to these pseudo charge-sheets, heavily twists the energy bands in the quantum well and the QCSE is more pronounced. This energy band bending induces a red shift in optical transitions between confined energy levels in quantum wells. When the injection voltage level is increased through the $\mu$ LED, the piezo-electric field is slowly screened and the energy bands are less warped. The red shift linked to QCSE is then recovered and slowly vanishes turning into a blue shift. Nevertheless, blue shift elucidations are still debated in literature.

\subsection{Quantum well excited-levels filling hypothesis}

We present on figure 7, normalized intensity electroluminescence spectra at four different voltage values, recorded on the $6 \mu \mathrm{m} \mu \mathrm{LED}$. At low bias, close to $\mathrm{V}_{\text {TO }}$, one wavelength peak centered at $520 \mathrm{~nm}$ is observable (red curve). This peak corresponds to the mean indium content incorporated in the InGaN quantum well. When the voltage increases, we observe the formation of new emission peaks alongside the first one. At $3.5 \mathrm{~V}$, beside the $520 \mathrm{~nm}$ peak, we perceive the appearance of a higher intensity one, centered at $508 \mathrm{~nm}$, and a slight hump at $480 \mathrm{~nm}$ (green curve). After increasing the bias by $2 \mathrm{~V}$, (blue curve) the $480 \mathrm{~nm}$ intensity takes over the two precedent higher wavelength peaks, and a hump at $460 \mathrm{~nm}$ begins to appear. This later shows the same luminescence intensity as the $480 \mathrm{~nm}$ peak when voltage is raised to $7.5 \mathrm{~V}$ (purple curve). At this bias level, both precedent peaks $(520 \mathrm{~nm}$ and $508 \mathrm{~nm})$ appear as small bulges compared to the high energy peaks $(460 \mathrm{~nm}$ and $480 \mathrm{~nm})$. The discrete wavelength peaks tend to demonstrate that high energy excited levels inside quantum wells are progressively populated at high injection levels. This permits the appearance of higher energy, hence shorter wavelength optical transitions. This wavelength and peak intensity ballet versus injection bias is a plausible elucidation of the green to blue shift in our $\mu$ LEDs.

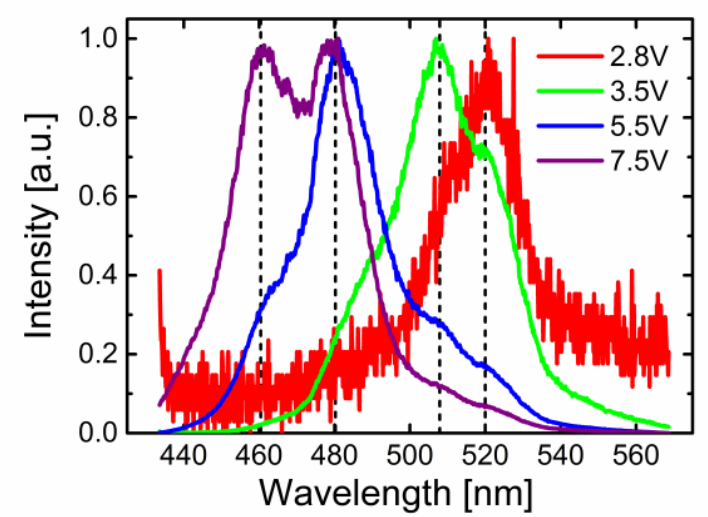

Figure 7. Normalized electroluminescence spectra versus bias carried out on a $6 \mu \mathrm{m}$ diameter $\mu$ LED. In contrary to what is usually believed, the blue shift in InGaN/GaN $\mu$ LEDs is not solely due to the QCSE. The appearance of discrete emission peaks with variable intensities depending on injection bias level tends to corroborate the filling of high excited levels in the quantum wells explaining the color changing behavior in green $\mu$ LEDs.

\section{CONCLUSION}

InGaN/GaN based green $\mu \mathrm{LEDs}$ are less debated in literature compared to blue emitting ones. One main reason is the difficulty to incorporate high indium content in InGaN alloys. Yet, they are good candidates for simple see-through applications as the eye sensitivity to green is at its maximum. We have exposed through an electro-optical thorough analysis of different sized green $\mu$ LEDs that their quantum efficiency behavior is far from being easily described by an easy ABC model. In addition, they show a less effective QCSE at their edges. The light emission homogeneity study also reveals an indium content dispersion inside quantum wells. The electroluminescence measurements divulges a drastic green to blue color shift. Beside QCSE reduction in $\mu$ LEDs under bias, we suspect the filling of high energy levels in quantum wells as a likely explanation of this shift. Finally, this paper aims to a better understanding of InGaN/GaN based green $\mu$ LEDs features, by a very first investigation of size effect on their electro-optical behavior. 


\section{ACKNOWLEDGEMENTS}

The authors acknowledge partial fundings from the European Union's Horizon 2020 VOSTARS research and innovation programme under grant agreement No 731974 and H2020 HILICO European project (H2020- JTI-CS2-2016-CFP04-SYS01-03, Grant No. 755497).

\section{REFERENCES}

[1] Day, J., Li, J., Lie, D. Y. C., Bradford, C., Lin, J. Y., Jiang, H. X., "III-Nitride full-scale high-resolution microdisplays", Appl. Phys. Lett., 99, 031116 (2011).

[2] Templier, F., Dupré, L., Tirano, S., Marra, M., Verney, V., Olivier, F., Aventurier, B., Sarrasin, D., Marion, F., Catelain, T., Berger, F., Mathieu, L., Dupont, B., Gamarra, P., "GaN-based Emissive Microdisplays: A very Promising Technology for Compact, Ultra-high Brightness Display Systems”, SID Int. Symp. Digest Tech. Papers, 47(1), pp. 1013-1016, (2016).

[3] El-Ghoroury, H. S., Alpaslan, Z. Y., "Quantum Photonic Imager (QPI): A New Display Technology and its Applications", Proc. of the $21^{\text {st }}$ International Display Workshop (IDW'14), Niigata, Japan (2014).

[4] Olivier, F., Tirano, S., Dupré, L., Aventurier, B., Largeron, C., Templier, F., "Influence of size reduction on the performances of GaN-based micro-LEDs for display application”, J. Lumin., 191, pp.112-116, (2017).

[5] Olivier, F., Daami, A., Licitra, C., Templier, F., "Shockley-Read-Hall and Auger non-radiative recombination in GaN based LEDs: A size effect study", Appl. Phys. Lett., 111, 022104, (2017).

[6] Daami, A., Olivier, F., Sarrasin, D., Dupré, L., Templier, F., "InGaN/GaN $\mu$ LEDS for display applications optical and electrical characteristics spread comprehension", Proc. Int. Conf. SSDM, Sendai, Japan, (2017).

[7] Dupré, L., Marra, M., Verney, V., Aventurier, B., Henry, F., Olivier, F., Tirano, S., Daami, A., Templier, F., "Processing and characterization of high resolution GaN/InGaN LED arrays at 10 micron pitch for micro display applications," Proc. SPIE, Vol. 10104, 1010422, (2017).

[8] Terano, A., Imadate, H., Shiojima, K., "Mapping etching induced damages on GaN surfaces using scanning internal photoemission microscopy”, Mater. Sci. Semicond. Process., 70, Supp. C, 92-98, (2017).

[9] Choi, K. J., Jang, H. W., Lee, J.-L., "Observation of inductively coupled-plasma-induced damage on n-type GaN using deep-level transient spectroscopy”, Appl. Phys. Lett., 82, 1233-1235, (2003).

[10] Xie, E. Y., Chen, Z. Z., Edwards, P. R., Gong, Z., Liu, N. Y., Tao, Y. B., Zhang, Y. F., Chen, Y. J., Watson, I. M., Gu, E., Martin, R. W., Zhang, G. Y., Dawson, M. D., "Strain relaxation in InGaN/GaN micro-pillars evidenced by high resolution cathodoluminescence hyperspectral imaging”, J. Appl. Phys. 112, 013107, (2012).

[11] Hangleiter, A., Hitzel, F., Netzel, C., Fuhrmann, D., Rossow, U., Ade, G., Hinze, P., "Suppression of Nonradiative Recombination by V-Shaped Pits in GaInN/GaN Quantum Wells Produces a Large Increase in the Light Emission Efficiency”, Phys. Rev. Lett. 95, 127402, (2005).

[12] Vaitkevicius, A., Mickevicius, J., Dobrovolskas, D., Tuna O., Giesen, C., Heuken, M., Tamulaitis, G., "Influence of quantum-confined Stark effect on optical properties within trench defects in InGaN quantum wells with different indium content”, J. Appl. Phys. 115, 213512, (2014).

[13]Liu, Q. Z., Lau, S. S., “A review of the metal-GaN contact technology” Solid-State Electron., 42(5), 677-691, (1998).

[14] Ho, J.-K., Jong, C.-S., Chiu, C. C., Huang, C.-N., Chen, C.-Y., Shih, K.-K., "Low-resistance ohmic contacts to p-type GaN", Appl. Phys. Lett., 74(9), 1275-1277, (1999).

[15] Fiorentini, V., Bernardini, F., Della Sala, F., Di Carlo, A., Lugli, P., "Effects of macroscopic polarization in IIIV nitride multiple quantum wells", Phys. Rev. B, 60(12), 8849-558, (1999). 